\title{
Comparison of the Mechanical Properties of Different Tendon Profiles with External Prestressed Reinforcement
}

\author{
Xiangong ZHOU, Chenglin FU, Wei HOU, Haofei GUO, Wenliang HU*
}

\begin{abstract}
As a common method, external prestressing widely informs rehabilitation in existing structures. This paper presents the total prebending moment calculation of external prestressing with different tendon profiles. Meanwhile, the external prestressing loss and original internal prestressing loss are considered in the calculation in both the theoretical method and the finite element method. Then, we discuss the reinforcement efficiency of different tendons profiles and provide the reinforcement distribution ratio. The results show that the theoretical method is similar to the finite element method, and it can quickly evaluate the reinforcement effect by using different tendon profiles in engineering. By comparing the reinforcement efficiency under different external tendon profiles, the reinforcement scheme is determined according to the local damage and the overall damage of the beam, which effectively decreases the cost of reinforcement.
\end{abstract}

Keywords: continuous beam; external prestressing; prestressing loss; reinforcement effectiveness; tendon profiles

\section{INTRODUCTION}

With the growth in bridge service time, the damages caused by heavier traffic loads, progressive structural aging, and corrosion of steel reinforcement have become an increasingly prominent issue. To improve the service property of bridges, many types of reinforcement and maintenance methods have been proposed [1-3]. External prestressing as a common method widely used in rehabilitation of existing structures [4-8], where prestressing tendons are placed outside of a concrete section, is an attractive technique in new construction and the strengthening of existing structures due to its ability to actively control stresses and deflections, speed of replacement, and ease of inspection under service conditions.

Until now, studies on the external prestressed structure and reinforcement technology include many aspects. For example, ref. [9] studied the effect of several factors on the increase in ultimate stress in external Parafil ropes and external steel tendons. Ref. [10] presented a brief overview of bonded anchorage applications and discussed three methods of mechanical anchorage: spike, wedge and clamping. Ref. [11] verified the correctness and precision of the calculation theories in connection with prestressing loss by examining various losses due to friction resistance, anchor deformation, concrete elastic compression, timedependent variations. Ref. [12] presented the test results on 12 two-span continuous T-beams, which were strengthened using different external tendon types and profiles and subjected to third-point loadings. Refs. [13-18] examined the overall behavior of FRP-reinforced and strengthened concrete members. Ref. [19] simulated the flexural behaviors of RC (reinforced concrete) beam strengthened by prestressed HFRP sheets. Early research focused on the ultimate bearing capacity of the external prestressed structure, calculation of the ultimate stress increase of the external tendons, secondary reactions due to the prestressing effect, prestressing loss of the external tendons, design of the anchor blocks and steering blocks, etc. However, studies on the external prestressed reinforcement technology of the PC continuous beam bridge were rare and mostly based on external prestressed new-built structure. Later, some studies were conducted on the local structure in the external prestressed reinforcement, and most of the research objects were concrete turning blocks and anchor blocks. The main research method was analyzing the stress state and stress distribution form of the local structure by establishing finite element models. Although there is a preliminary discussion for the external prestressed reinforcement design of a PC continuous beam bridge, more theoretical calculation methods must be performed.

This paper considers the prestressing loss of internal and external tendons, and presents the mechanical calculation formulas of the total prebending moment of external prestressing tendons with different profiles. Finally, we compare the reinforcement efficiency under different external tendon profiles to determine a reasonable reinforcement scheme.

\section{TOTAL PRE-MOMENT CALCULATION METHODS WITH DIFFERENT TENDON PROFILES}

The total premoment calculation methods of the statically indeterminate structures are mainly divided into the force method, equivalent load method, bending moment area method, constrained secondary bending moment method and fixed end bending moment method. The force method is used to solve the total premoment of three-equal-span PC continuous beams with different forms of external cable reinforcement.

To simplify the calculation, the total premoment calculation of the external cable-reinforced three-equalspan PC continuous beams assumes that:

(1) The section of the main girder is equal, and the effects of axial deformation and shear deformation are omitted. The section bending stiffness is EI after the external prestressed reinforcement.

(2) The positive bending moment refers to the bottom of the section being pulled, while the negative bending moment indicates that the top of the section is pulled.

(3) The effective prestressed value of the external tendons after reinforcement is $N_{\mathrm{P}}$. 


\subsection{Straight-Line Reinforcement in the Positive-Bending- Moment Area}

The straight-line reinforcement in the positivebending-moment area is a local reinforcement technology for damages at the mid-span of the PC continuous beam. The straight-line reinforcement method can effectively prevent the increase in the negative bending moment and unfavorable mechanical situation near the support when the long external prestressing tendons are used to strengthen the middle section. The straight-line external tendons in the positive-moment area are arranged as shown in Fig. 1a, and the total premoment of the three-equal-span $\mathrm{PC}$ continuous beam after reinforcement is shown in Fig. $1 b$.

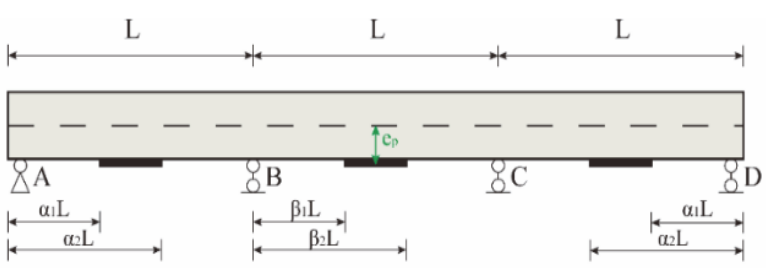

(a)

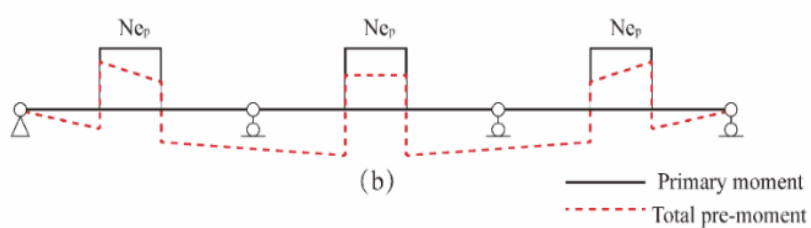

Figure 1 Internal force analysis of straight-line reinforcement in positive bending moment area of three-equal-span PC continuous beam: (a) Straight-line tendons in positive bending moment area; (b) Moment of external prestressed beam

The total premoment of sections after the straight-line reinforcement in the positive-moment area is shown in Eq. (1):

$M=M_{\mathrm{p}}+X_{1} \bar{M}_{1}+X_{2} \bar{M}_{2}$

The force equation is established as $\boldsymbol{\delta} \boldsymbol{X}+\boldsymbol{\Delta}_{\mathrm{p}}=\boldsymbol{0}$; then, the Diagrammatic Multiplication Method is used to solve each partial coefficient as follows:

$\delta_{11}=\delta_{22}=\frac{2}{3 E I} L$

$\delta_{12}=\delta_{21}=\frac{1}{6 E I} L$

$\Delta_{\mathrm{lp}}=-\frac{L}{2 E I}\left[\left(\alpha_{2}^{2}-\alpha_{1}^{2}\right)+\left(2-\beta_{1}-\beta_{2}\right)\left(\beta_{2}-\beta_{1}\right)\right] N_{\mathrm{p}} e_{\mathrm{p}}$

$\Delta_{2 \mathrm{p}}=-\frac{L}{2 E I}\left[\left(\alpha_{2}^{2}-\alpha_{1}^{2}\right)+\left(\beta_{2}^{2}-\beta_{1}^{2}\right)\right] N_{\mathrm{p}} e_{\mathrm{p}}$

Bringing Eq. (2), Eq. (3), Eq. (4), and Eq. (5) into the force equation; then, basic unknown force vectors as shown in Eq. (6) and Eq. (7) introduce force vectors back to Eq. (1) to obtain the total premoment value.

$$
\begin{aligned}
& X_{1}=\left[\frac{3}{5}\left(\alpha_{2}^{2}-\alpha_{1}^{2}\right)+\left(\beta_{2}-\beta_{1}\right)\left(\frac{8}{5}-\beta_{1}-\beta_{2}\right)\right] N_{\mathrm{p}} e_{\mathrm{p}} \\
& X_{2}=\left[\frac{3}{5}\left(\alpha_{2}^{2}-\alpha_{1}^{2}\right)+\left(\beta_{2}-\beta_{1}\right)\left(\beta_{1}+\beta_{2}-\frac{2}{5}\right)\right] N_{\mathrm{p}} e_{\mathrm{p}}
\end{aligned}
$$

\subsection{Straight-Line Reinforcement in the Negative-Bending- Moment Area}

The straight-line reinforcement in the negativebending-moment area is a local reinforcement technology for damages near the supports of the PC continuous beam. Using the long external prestressing tendons to strengthen the supports may cause the increment in positive bending moment and unfavorable mechanical situation at the middle section. The negative-bending-moment area reinforcement can effectively prevent the moment of middle section from increasing. Fig. $2 a$ and Fig. $2 b$ indicate the straight-line external tendons in the negative-bendingmoment area, and the basic unknown force vectors are shown in Eq. (8) and Eq. (9).

$$
\begin{aligned}
& X_{1}=\frac{3}{5}\left(\gamma_{1}^{2}-2 \gamma_{1}-2 \gamma_{2}\right) N_{\mathrm{p}} e_{\mathrm{p}} \\
& X_{2}=\frac{3}{5}\left(\gamma_{1}^{2}-2 \gamma_{1}-2 \gamma_{2}\right) N_{\mathrm{p}} e_{\mathrm{p}}
\end{aligned}
$$

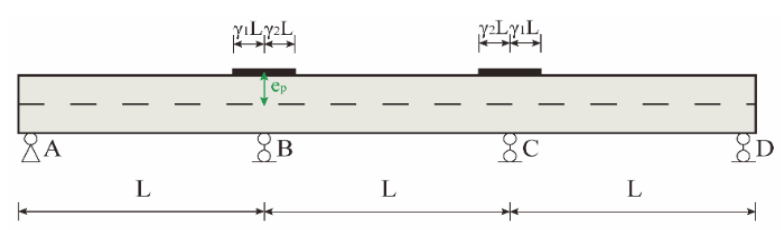

(a)

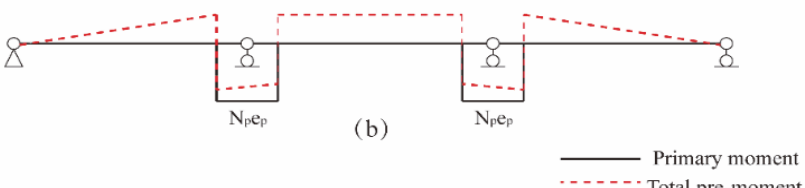

Figure 2 Internal force analysis of straight-line reinforcement in negative bending moment area of three-equal-span PC continuous beam: (a) Straight-line tendons in negative bending moment area; (b) Moment of external prestressed beam
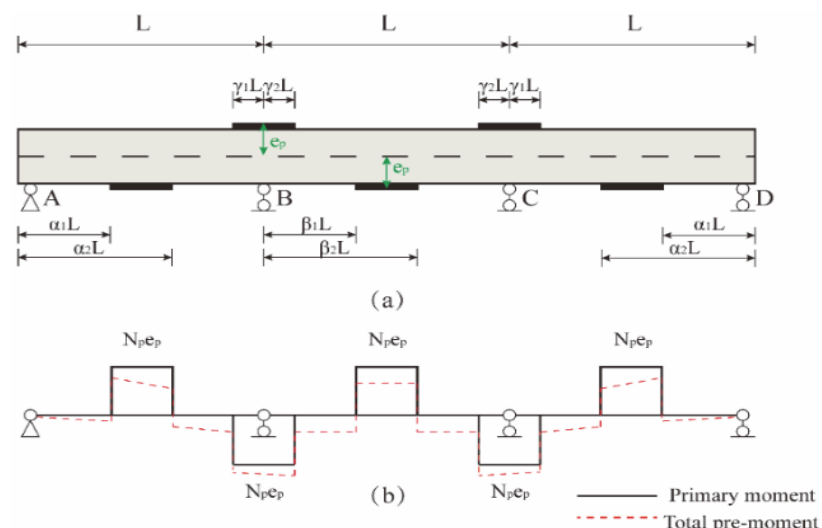

Figure 3 Internal force analysis of straight-line reinforcement in positive and negative bending moment area of three-equal-span PC continuous beam:(a) Straight-line tendons in positive and negative bending moment area; (b) Moment of external prestressed beam 


\subsection{Straight-Line Reinforcement in the Positive and Negative-Bending-Moment Area}

Straight-line reinforcement in the positive and negative-bending-moment area is a reinforcement technique used for the damages of PC continuous beams. As shown in Fig. 3a and Fig. 3b, the straight line reinforced tendons are used in the positive and negative-bendingmoment areas, and the basic unknown force vectors are shown in Eq. (10) and Eq. (11).

$$
\begin{aligned}
& X_{1}=\left[\frac{3}{5}\left(\alpha_{2}^{2}-\alpha_{1}^{2}\right)+\left(\beta_{2}-\beta_{1}\right)\left(\frac{8}{5}-\beta_{1}-\beta_{2}\right)\right] N_{\mathrm{p}} e_{\mathrm{p}}+ \\
& +\frac{3}{5}\left(\gamma_{1}^{2}-2 \gamma_{1}-2 \gamma_{2}\right) N_{\mathrm{p}} e_{\mathrm{p}}
\end{aligned}
$$$$
X_{2}=\left[\frac{3}{5}\left(\alpha_{2}^{2}-\alpha_{1}^{2}\right)+\left(\beta_{2}-\beta_{1}\right)\left(\beta_{1}+\beta_{2}-\frac{2}{5}\right)\right] N_{\mathrm{p}} e_{\mathrm{p}}+
$$$$
+\frac{3}{5}\left(\gamma_{1}^{2}-2 \gamma_{1}-2 \gamma_{2}\right) N_{\mathrm{p}} e_{\mathrm{p}}
$$

\subsection{Folding-Line Reinforcement in the Positive and Negative-Bending-Moment Area}

Fig. 4a and Fig. 4b show the positive and negative bending moments are reinforced by folding-line tendons, which are a more widely used profile in external prestressing reinforcement. The external tendons change the direction by steering blocks to realize the reinforcement in both positive and negative bending moments. The basic unknown force vectors are shown in Eq. (12) and Eq. (13).

$$
\begin{aligned}
& X_{1}=\left[\frac{3}{5}\left(\alpha_{2}^{2}-\alpha_{1}^{2}\right)+\left(\beta_{2}-\beta_{1}\right)\left(\frac{8}{5}-\beta_{1}-\beta_{2}\right)\right] N_{\mathrm{p}} e_{\mathrm{p}}+ \\
& +\frac{3}{5}\left(\gamma_{1}^{2}-2 \gamma_{1}-2 \gamma_{2}\right) N_{\mathrm{p}} e_{\mathrm{p}} \\
& X_{2}=\left[\frac{3}{5}\left(\alpha_{2}^{2}-\alpha_{1}^{2}\right)+\left(\beta_{2}-\beta_{1}\right)\left(\beta_{1}+\beta_{2}-\frac{2}{5}\right)\right] N_{\mathrm{p}} e_{\mathrm{p}}+ \\
& +\frac{3}{5}\left(\gamma_{1}^{2}-2 \gamma_{1}-2 \gamma_{2}\right) N_{\mathrm{p}} e_{\mathrm{p}}
\end{aligned}
$$

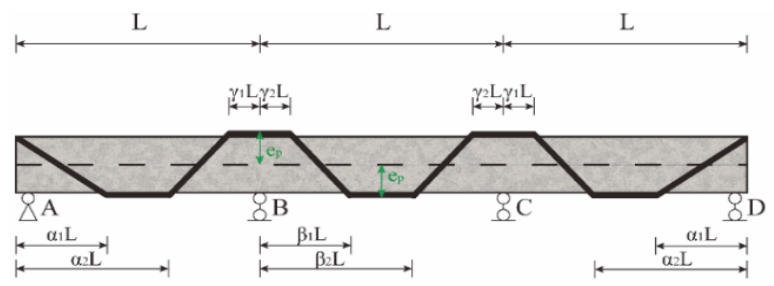

(a)

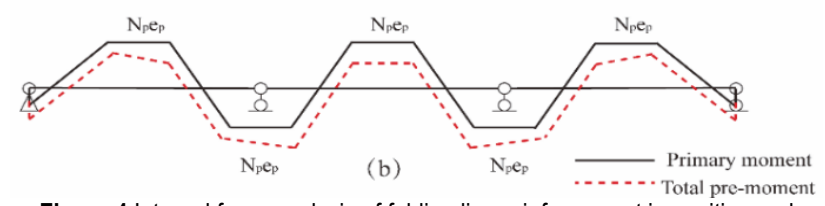

Figure 4 Internal force analysis of folding line reinforcement in positive and negative bending moment area of three-equal-span PC continuous beam:(a)

Folding -line tendons in positive and negative bending moment area; (b) Moment of external prestressed beam

\section{NUMERICAL SIMULATION FOR EXTERNAL PRESTRESSED BEAM}

The numerical model is a continuous cast in situ beam with constant-span prestressed concrete. The bridge span is $3 \times 35 \mathrm{~m}$, and the width is $16 \mathrm{~m}$. The full-bridge model is established using the finite element software Midas Civil. The external prestressing simulation is connected by coupling concrete and prestressing tendons. The shrinkage and creep changes of concrete are usually too small to be considered in old bridges that must be reinforced. The geometric model is shown in Fig. 5.

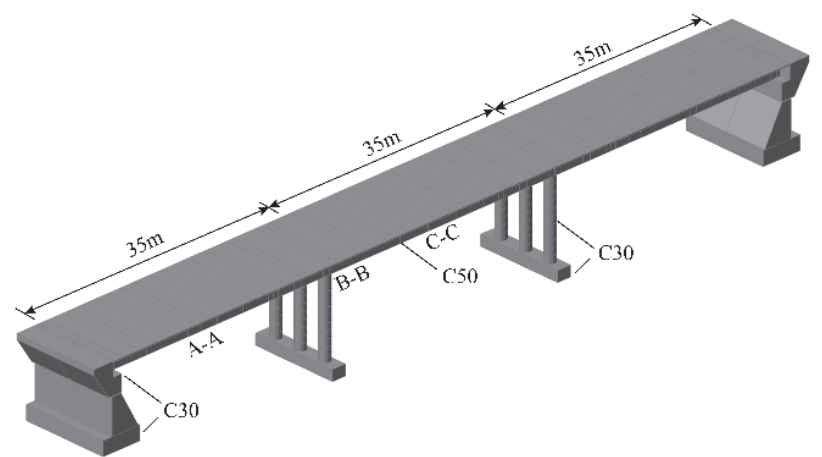

Figure 5 Finite element model of prestressed concrete continuous beam bridge

To analyze the effect of prestressing on the main beam, the loads in the model include the dead loads of each component and the prestressing load. (1) Dead loads: including the beam $\left(26 \mathrm{kN} / \mathrm{m}^{3}\right)$ and pavement layer $(71.2$ $\mathrm{kN} / \mathrm{m}$ ). (2) Prestressing force: the tension of prestressing is $1395 \mathrm{MPa}$.

The material in the bridge follows the Chinese Code [20]. The concrete in the main beam and pier is C50 and C30 respectively, the prestressing tendons are 1860 steel strands with a cross section of $1960 \mathrm{~mm}^{2}$, and the ordinary steel bars are HRB400 and HPB300. Specific parameters of each material are shown in Tab. 1.

Table 1 Materials property of cast-in-situ beam

\begin{tabular}{|l|c|c|c|c|c|}
\hline \multicolumn{1}{|c|}{ Property } & $\mathrm{C} 50$ & $\mathrm{C} 30$ & $\begin{array}{c}\text { Prestressed } \\
\text { tendons }\end{array}$ & HRB400 & HPB300 \\
\hline $\begin{array}{l}\text { Elasticity modulus / } \\
\mathrm{MPa}\end{array}$ & 34500 & 30000 & 195000 & 205000 & 205000 \\
\hline Unit weight / kN/m 3 & 25 & 25 & 7850 & 7850 & 7850 \\
\hline Poisson ratio & 0.167 & 0.167 & 0.3 & 0.3 & 0.3 \\
\hline $\begin{array}{l}\text { Compression } \\
\text { strength / MPa }\end{array}$ & 32.4 & 20.1 & $/$ & $/$ & $/$ \\
\hline $\begin{array}{l}\text { Tensile strength / } \\
\mathrm{MPa}\end{array}$ & 2.65 & 2.01 & $/$ & $/$ & $/$ \\
\hline $\begin{array}{l}\text { Yield strength / } \\
\mathrm{MPa}\end{array}$ & $/$ & $/$ & 1860 & 360 & 270 \\
\hline
\end{tabular}

\section{VALIDATION OF THE THEORETICAL METHOD}

The internal prestressing loss of the original beam due to the addition of external prestressing is considered, and we calculate the primary moment and secondary moment under the prestressing loss of external prestressing. Then, the total premoment is determined by analyzing a strengthened PC continuous beam with different forms of external prestressing distribution. The terms are defined in this section as follows: the first moment after deducting the prestressing loss of the external tendons itself is the nominal prestress degree. The second moment after 
deducting the prestressing loss of the external tendons and internal prestressing loss of the original structure is considered to be the true prestress degree. The ratio of real prestress degree to nominal prestress degree is the efficiency of reinforcement.

\subsection{Different Reinforcement Methods Result in Comparison}

(1) Straight-line reinforcement in the positivebending-moment area.

The three-equal-span PC continuous beam bridge is reinforced by straight-line external tendons in the positivebending-moment area, and the mechanical properties of PC continuous beam bridge are analyzed by the theoretical analytical method and finite element simulation method. The changes in bending moment in the key section of the beam before and after the reinforcement by the two calculation methods are shown in Fig. 6. The moment value "+" indicates that the bottom edge of the section is in tension; "-" indicates that the top edge of the section is in tension; $\mathrm{A}$ is the middle of the side-span, $\mathrm{B}$ is the support position, and $\mathrm{C}$ is the middle of the mid-span.

Thus, the bending moment variations of the beam before and after the reinforcement calculated by two calculation methods are close. Each part proportion of the external prestressing is relatively different. For the middle section of the side-span, the secondary moment, internal prestressing loss, and total premoment account for $32.69 \%$, $5.02 \%, 62.28 \%$ (reinforcement efficiency) of the primary moment, respectively. For the middle section of the midspan, the secondary moment, internal prestressing loss, and total premoment account for $64.85 \%, 2.23 \%, 32.92 \%$ (reinforcement efficiency) of the primary moment, respectively.
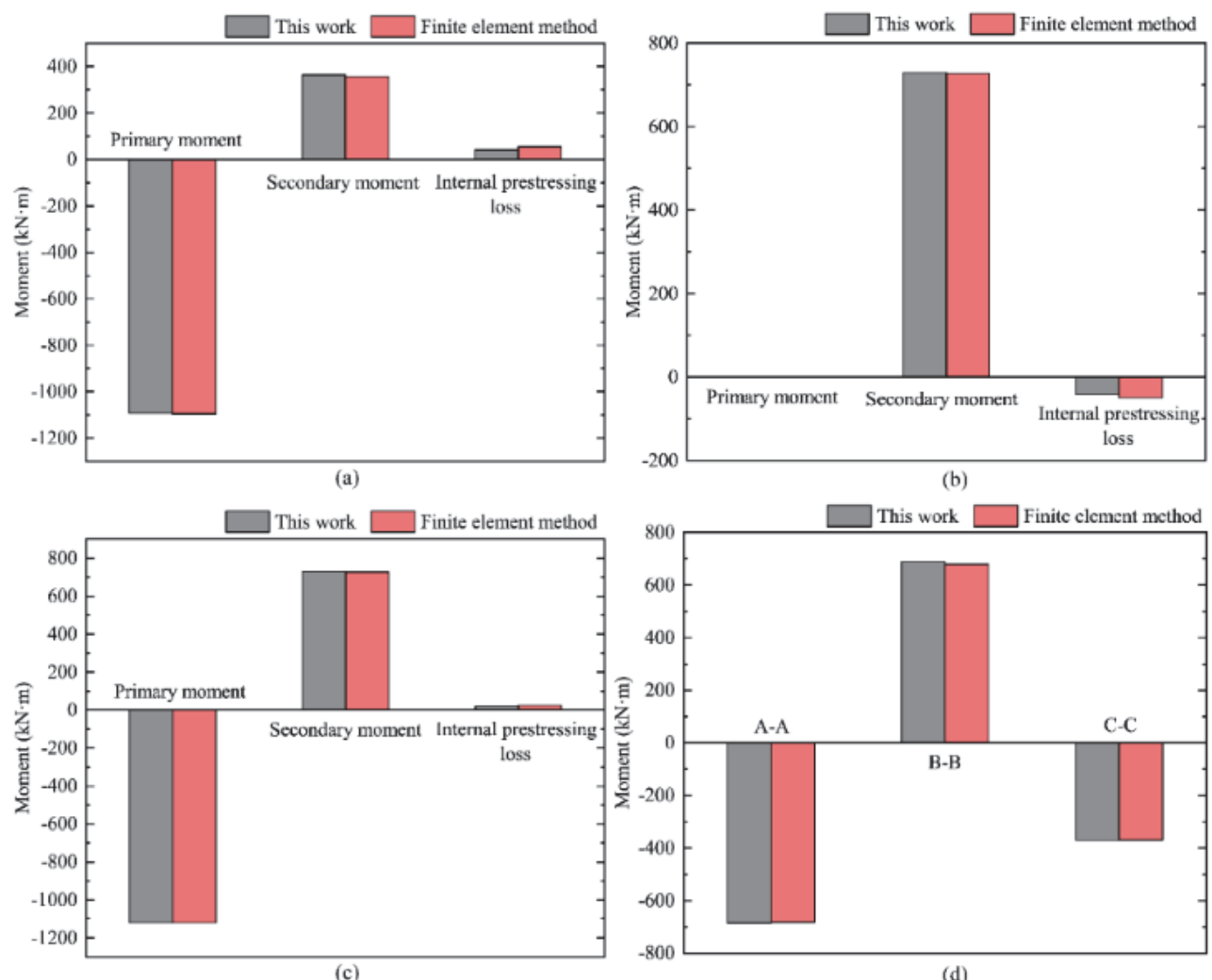

Figure 6 Results comparsion of key cross sections: (a)A-A (b) B-B (c) C-C (d) Total pre-moment

(2) Straight-line reinforcement in negative-bendingmoment area.

The straight-line reinforcement in the negativebending-moment area is used to strengthen the three-equalspan PC continuous beam bridge. Fig. 7 illustrates the bending moment change values of the key section of the beam before and after the reinforcement by comparing the results between theoretical analytical and finite element.

The results show that the bending moment variations of the beam before and after the reinforcement calculated by two calculation methods are close. The secondary moment, internal prestressing loss, and total premoment account for $30.83 \%, 1.94 \%$, and $67.23 \%$ (the reinforcement efficiency) of the primary moment in the support bearing section, respectively.

(3) Straight-line reinforcement in positive and negative-bending-moment area.

The results of the three-equal-span PC continuous beam bridge reinforced by straight-line reinforcement in the positive and negative-ending-moment areas are shown in Fig. 8. In the middle section of the side-span, the secondary moment, internal prestressing loss and total premoment account for $14.72 \%, 5.48 \%$ and $79.71 \%$ of the primary moment respectively, in the case of the finite element method. In the middle section of the mid-span, the secondary moment, internal prestressing loss and total premoment account for $29.25 \%, 3.22 \%$ and $67.62 \%$ of the primary moment. In the section of support, the secondary moment, internal prestressing loss and total premoment account for $25.33 \%, 5.89 \%$ and $119.44 \%$ of the primary moment. 

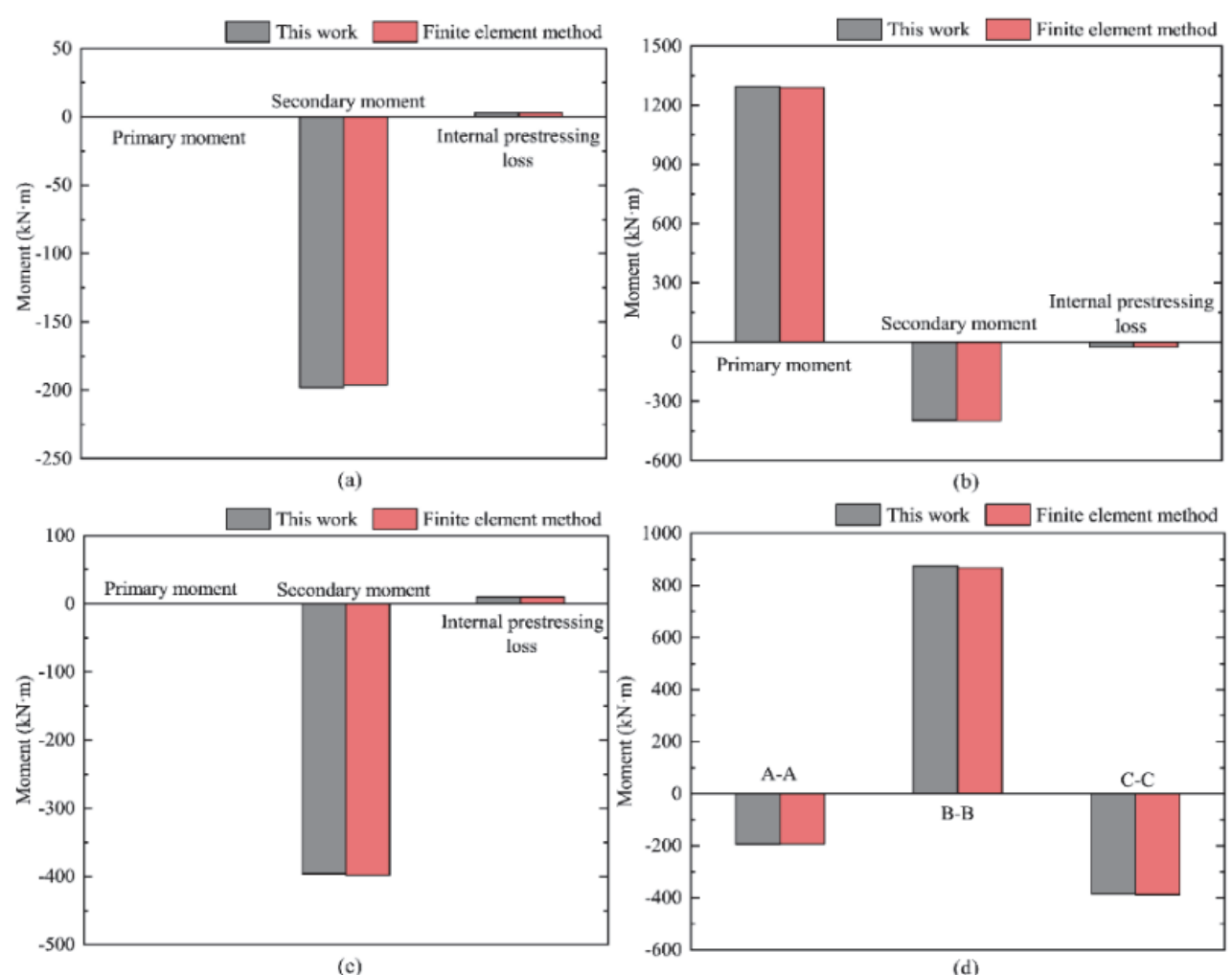

Figure 7 Results of comparsion of key cross sections: (a)A-A (b) B-B (c) C-C (d) Total pre-moment
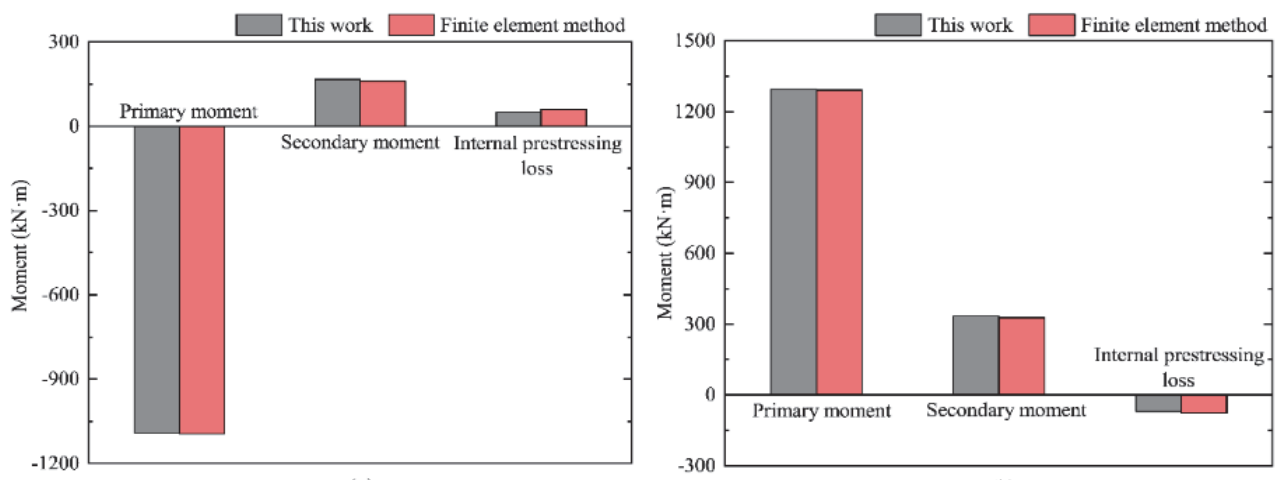

(a)

(b)
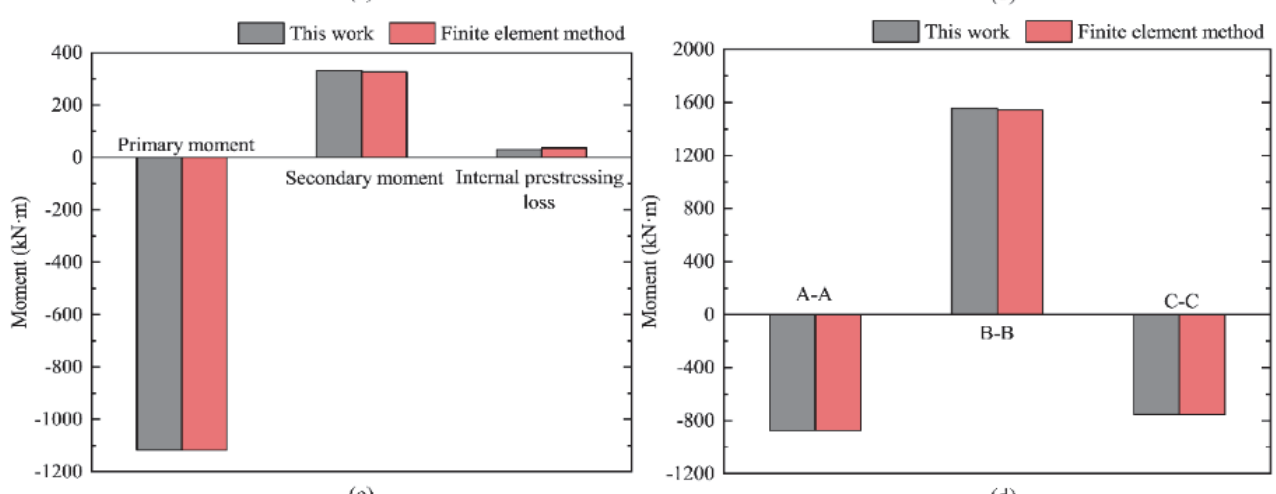

Figure 8 Results of comparsion of key cross sections: (a)A-A (b) B-B (c) C-C (d) Total pre-moment

(4) Folding-line reinforcement in positive and negative-bending-moment area.

Fig. 9 shows that the beam is reinforced by the folding line in the positive and negative-bending-moment area, and the theoretical value of the key section slightly differs from the finite element value. In the middle section of the sidespan, the secondary moment, internal prestressing loss and total premoment account for $11.38 \%, 5.61 \%$ and $83.01 \%$ of the primary moment respectively. In the middle section of the mid-span, the secondary moment, internal prestressing loss and total premoment account for $25.53 \%$, $3.72 \%$ and $70.05 \%$ of the primary moment in the case of the finite element method. In the section of bearing support, the secondary moment, internal prestressing loss and total premoment account for $19.00 \%, 5.83 \%$ and $113.17 \%$ of the primary moment respectively. 

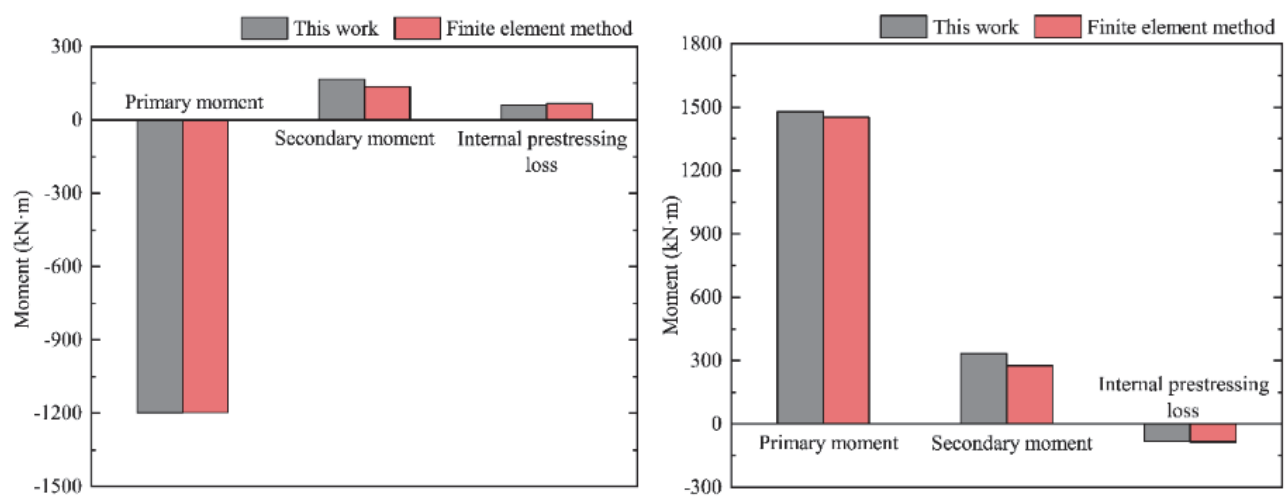

(b)

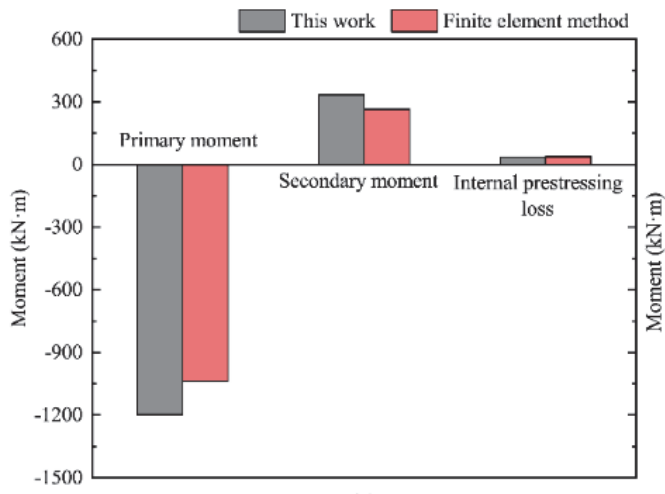

(c)

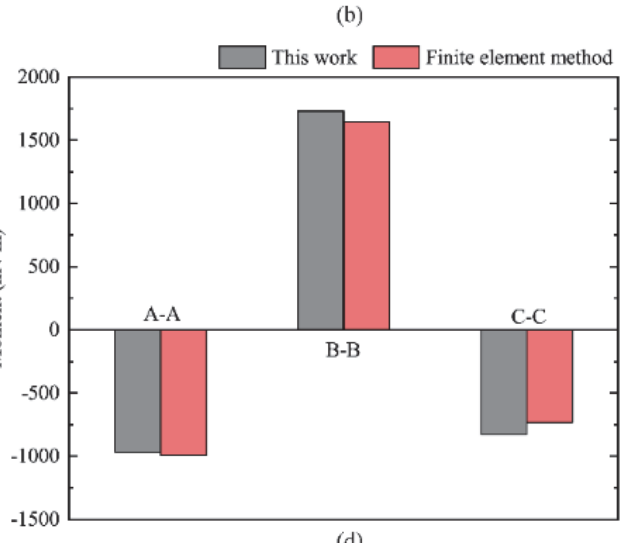

Figure 9 Results of comparsion of key cross sections: (a)A-A (b) B-B (c) C-C (d) Total pre-moment

\subsection{Reinforcement Efficiency of Different Reinforcement Forms}

The reinforcement effectiveness in key sections of the beam with different reinforcement forms is shown in Tab. 2.

Tab. 2 shows that when the straight-line reinforcement is adopted in the positive-bending-moment area, the reinforcement efficiency is obtained in the middle section of the side-span (A-A) and the mid-span (C-C). In contrast, when the straight-line reinforcement is adopted in the negative-bending-moment area, the reinforcement efficiency is only obtained in the supports (B-B). Therefore, the external tendons can be arranged according to the damage condition. When the entire beam is seriously damaged, the external tendons can be arranged in the positive-moment area and negative-moment area. Comparing the forms of straight-line reinforcement and folding-line reinforcement, we observe that the reinforcement efficiency of the folding-line reinforcement is $3.3 \%$ and $3.13 \%$ higher than that of the straight line in the positive-bending-moment area. However, the reinforcement efficiency of the support section has decreased by $6.27 \%$. Therefore, the positive-moment area and negative-moment area of the beam that must be reinforced is determined according to the serious situation.

Table 2 Reinforcement efficiency of key sections of main beam under different reinforcement forms

\begin{tabular}{|c|c|c|c|c|}
\hline \multirow{2}{*}{$\begin{array}{c}\text { Section } \\
\text { Position }\end{array}$} & $\begin{array}{c}\text { Straight-line reinforcement } \\
\text { in positive bending moment } \\
\text { area }\end{array}$ & $\begin{array}{c}\text { Straight-line reinforcement } \\
\text { in negative bending moment } \\
\text { area }\end{array}$ & $\begin{array}{c}\text { Straight-line reinforcement in } \\
\text { positive and negative bending } \\
\text { moment area }\end{array}$ & $\begin{array}{c}\text { Folding line reinforcement in positive } \\
\text { and negative bending moment area }\end{array}$ \\
\hline A-A & 62.28 & 0 & 79.71 & 83.01 \\
\hline B-B & 0 & 67.23 & 119.44 & 113.17 \\
\hline C-C & 32.92 & 0 & 67.62 & 70.75 \\
\hline
\end{tabular}

Note: The reinforcement efficiency is the ratio of the true degree of prestressing to the nominal degree of prestressing.

\section{CONCLUSIONS}

This paper investigated the reinforcement efficiency of externally prestressed PC continuous beams through the calculation and analysis of four reinforcement forms (straight-line reinforcement in a positive-bending-moment area, straight-line reinforcement in a negative-bendingmoment area, straight-line reinforcement in a positive and negative-bending moment area, and folding-line reinforcement in positive and negative-bending-moment area). The mechanical calculation formulas of the total premoments of three-equal-span PC continuous beams with different external tendon profiles are provided.

The primary bending moment, secondary bending moment, internal prestressing loss, total prebending moment and reinforcement efficiency of the prestressed concrete continuous beam are analyzed by comparing the theoretical method and finite element external prestressing simulation method. They have similar results. Thus, the reinforcement scheme according to the calculation formulas in this paper can effectively save the cost of reinforcement. 


\section{REFERENCES}

[1] Béguin, G. H. (2018). Various Schemes for Strengthening Concrete Structures. Practice Periodical on Structural Design and Construction, 23(3), 06018004. https://doi.org/10.1061/(ASCE)SC.1943-5576.0000377

[2] Xu, Z., Chen, B., Zhuang, Y., Tabatabai, H., \& Hunag, F. (2018). Rehabilitation and Retrofitting of a Multispan Simply-Supported Adjacent Box Girder Bridge into a Jointless and Continuous Structure. Journal of Performance of Constructed Facilities, 32(1), 04017112. https://doi.org/10.1061/(ASCE)CF.1943-5509.0001107

[3] Wang, S., Ke, Z., Gao, Y., \& Zhang, Y. (2019). Long-Term In Situ Performance Investigation of Orthotropic Steel Bridge Deck Strengthened by SPS and RPC Solutions. Journal of Bridge Engineering, 24(6). 04019054. https://doi.org/10.1061/(ASCE)BE.1943-5592.0001421

[4] Alkhairi, F. M. \& Naaman, A. E. (1993). Analysis of Beams Prestressed with Unbonded Internal or External Tendons. Journal of Structural Engineering, 119(9), 2680-2700. https://doi.org/10.1061/(ASCE)0733-9445(1993)119:9(2680)

[5] Cardinale, G. \& Orlando, M. (2004). Structural Evaluation and Strengthening of a Reinforced Concrete Bridge. Journal of Bridge Engineering, 9(1), 35-42. https://doi.org/10.1061/(ASCE)1084-0702(2004)9:1(35)

[6] Shin, K. J., Lee, S. H., \& Kang, T. H. K. (2014). External Posttensioning of Reinforced Concrete Beams Using a VShaped Steel Rod System. Journal of Structural Engineering, 140(3), 04013067. https://doi.org/10.1061/(ASCE)ST.1943-541X.0000824

[7] Ferreira, D., Bairán, J. M., \& Marí, A. (2016). Shear strengthening of reinforced concrete beams by means of vertical prestressed reinforcement. Structure and Infrastructure Engineering, 12(3), 394-410. https://doi.org/10.1080/15732479.2015.1019893

[8] Dai, L., Wang, L., Deng, M., Wu, B., Floyd, R. W., \& Zhang, J. (2018). Strengthening a 20-Year-Old Post-Tensioned Concrete Box Beam with Double-Layer Prestressed Steel Wire Ropes. Journal of Bridge Engineering, 23(11), 05018009 . 5592.0001301

https://doi.org/10.1061/(ASCE)BE.1943-

[9] Ghallab, A. \& Beeby, A. W. (2005). Factors affecting the external prestressing stress in externally strengthened prestressed concrete beams. Cement and Concrete Composites, 27(9), 945-957. https://doi.org/10.1016/j.cemconcomp.2005.05.003

[10] Schmidt, J. W., Bennitz, A., Täljsten, B., Golterman, P., \& Pedersen, H. (2012). Mechanical anchorage of FRP tendonsA literature review. Construction and Building Materials 32. Strengthening and Retrofitting of concrete structures with Fiber Reinforced polymer material, 110-121. https://doi.org/10.1016/j.conbuildmat.2011.11.049

[11] Zhi-jian, H. \& Zhao-fang, H. (2006). Practical Estimation Method for Prestress Loss of Externally Prestressed Structures. Bridge Construction, (1), 73-75+82.

[12] Tan, K. H. \& Tjandra, R. A. (2007). Strengthening of RC Continuous Beams by External Prestressing. Journal of Structural Engineering, 133(2), 195-204. https://doi.org/10.1061/(ASCE)0733-9445(2007)133:2(195)

[13] DAntino, T. \& Pellegrino, C. (2014). Bond between FRP composites and concrete: Assessment of design procedures and analytical models. Composites Part B: Engineering 60, 440-456. https://doi.org/10.1016/j.compositesb.2013.12.075

[14] Lou, T., Lopes, S. M. R., \& Lopes, A. V. (2014). Factors affecting moment redistribution at ultimate in continuous beams prestressed with external CFRP tendons. Composites Part B: Engineering 66, 136-146. https://doi.org/10.1016/j.compositesb.2014.05.007

[15] Neto, P., Alfaiate, J., \& Vinagre, J. (2014). A threedimensional analysis of CFRP-concrete bond behaviour.
Composites Part B: Engineering 59, 153-165. https://doi.org/ 10.1016/j.compositesb.2013.11.025

[16]Nigro, E., Cefarelli, G., Bilotta, A., Manfredi, G., \& Cosenza, E. (2014). Guidelines for flexural resistance of FRP reinforced concrete slabs and beams in fire. Composites Part $B: \quad$ Engineering 58, 103-112. https://doi.org/ 10.1016/j.compositesb.2013.10.007

[17] Seo, S. Y., Feo, L., \& Hui, D. (2013). Bond strength of near surface-mounted FRP plate for retrofit of concrete structures. Composite Structures 95, 719-727. https://doi.org/10.1016/j.compstruct.2012.08.038

[18] Zhu, H., Dong, Z. Q., Wu, G., \& Chen, H. Y. (2017). Experimental Evaluation of Bent FRP Tendons for Strengthening by External Prestressing. Journal of Composites for Construction, 21(5), 04017032. https://doi.org/10.1061/(ASCE)CC.1943-5614.0000811

[19] Wang, X. \& Zhou, C. (2018). Numerical investigation for the flexural strengthening of reinforced concrete beams with external prestressed HFRP sheets. Construction and Building Materials 189, 804.815. https://doi.org/10.1016/j.conbuildmat.2018.08.219

[20] MOCAT (Ministry of Communications and Transportation) (2018) Code for design of reinforced concrete and prestressed concrete highway bridges and culverts. [In Chinese.] JTG 3362-2018. Beijing: MOCAT.

\section{Contact information:}

Xiangong ZHOU

Highway College, Chang'an University, Xi'an 710064, China

Chenglin FU

Highway College, Chang'an University, Xi'an 710064, China

Wei HOU

Highway College, Chang'an University, Xi'an 710064, China

Haofei GUO

Highway College, Chang'an University, Xi'an 710064, China

Wenliang HU

(Corresponding author)

Highway College, Chang'an University, Xi'an 710064, China

E-mail: 2015021022@chd.edu.cn 